\title{
COMPARATIVE STUDY REGARDING THE EFFECT OF DIFFERENT FINISHING AND POLISHING SYSTEMS ON A BULK-FILL COMPOSITE RESIN SURFACE

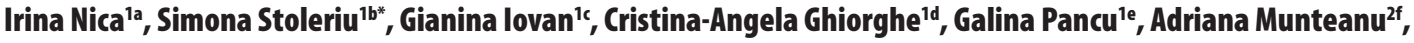 Sorin Andrian ${ }^{19}$
}

'Department of Odontology - Periodontology and Fixed Prosthodontics, Faculty of Dental Medicine, "Grigore T. Popa” University of Medicine and Pharmacy, Jassy, Romania

2Department of Machine Tools, Faculty of Machine Manufacturing and Industrial Management, "Gheorghe Asachi"Technical University, Jassy, Romania

\author{
${ }^{a} D D S$, PhD, Assistant Professor \\ b,c,fDDS, PhD, Associated Professor \\ d,eDDS, PhD, Lecturer \\ ${ }^{9} \mathrm{DDS}$, PhD, Professor
}

ABSTRACT

DOI: 10.25241/stomaeduj.2018.5(2).art.2

Introduction: One of the main objectives of composite restorations procedure is to obtain a smooth surface for aesthetic reasons and for oral health.

The aim of this study was to assess the surface morphology of a bulk fill composite material after finishing and polishing with three different finishing and polishing systems.

Materials and methods: Filtek Bulk Fill Posterior composite resin was chosen for this study (3M ESPE St. Paul, MN, USA). Twenty cylindrical samples $5 \mathrm{~mm}$ in diameter and $2 \mathrm{~mm}$ thick were made using plastic molds. They were randomly and equally assigned to four groups. In group 1 (control) the samples were not subjected to finishing and polishing procedure. In study groups 2-4, the samples were finished using two tungsten carbide burs and then polished using one step Occlubrush system (KerrHawe SA, Switzerland) - group 2, with the two step Sof-Lex system (3M ESPE) - group 3, and with the multi-step Super Snap system (Shofu, Inc. Kyoto, Japan) - group 4. The surface characteristics of the samples were quantitatively analyzed using profilometry and qualitatively evaluated by scanning electron microscopy. The Kolmogorov-Smirnov normality test was used to determine the distribution of data in groups. ANOVA and Tukey post hoc statistical tests were used to compare the results in groups.

Results: Finishing with tungsten carbide burs and two-steps Sof-Lex polishing system and one-step polishing system Occlubrush determined, higher roughness when comparing to multi-step Super Snap system.

Conclusion: The surface characteristics of the studied composite resin were influenced by the type of finishing and polishing system used.

Keywords: bulk-fill composite, finishing and polishing systems, profilometry, SEM.

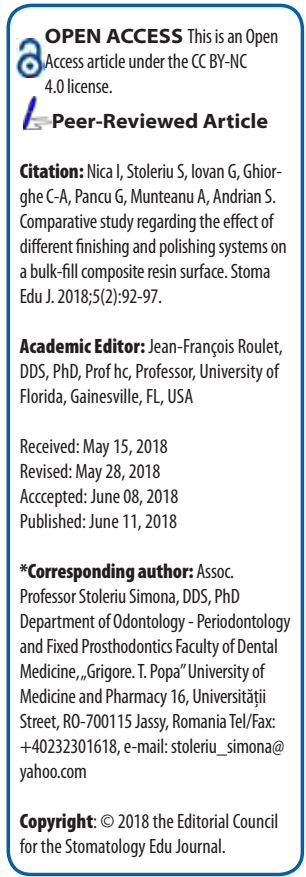

\section{Introduction}

Finishing and polishing are mandatory steps in direct restoration using composite resins. Obtaining a smooth surface has always been one of the main objectives of composite restorations, not only for aesthetic reasons but also for maintaining oral health [1].

It is considered that the surface roughness that leads to bacterial plaque retention is $0.2 \mu \mathrm{m}$ [2]. Surface roughness higher than this value makes the adherence of bacteria from the oral environment impossible to prevent. In time, biofilm accumulation is responsible for the decreased wear resistance of the restoration, increased risk of caries adjacent to restoration and periodontal inflammation. Surface roughness also influences the retention rate of extrinsic pigments and the aesthetic aspect of the restoration [3-5].

A wide range of instruments can be used to finish and polish direct restoration, such as carbide or diamond finishing burs, rubber based abrasives, aluminium oxide particle discs, abrasive strips and polishing pastes. The action of each instrument determines different values of roughness by the degree of flexibility of the substrate on which the abrasive powder is impregnated, by the hardness of the abrasive powder and by the diameter of the particles from which it is made and all these in relation to the structure of the composite material [6-8]. Aim The purpose of the present study was to evaluate the surface characteristics of a bulk fill composite resin used for direct restoration when different types of finishing and polishing systems were used. The surface microstructure was qualitatively evaluated by scanning electron microscopy (SEM) and quantitatively assessed by surface roughness determination using profilometry.

\section{Materials and Methods}

The material used in the present study was Filtek Bulk Fill Posterior Restorative (3M ESPE, St. Paul, MN, USA). Lot: N720858, shade A3. It was designed to be easily and quickly applied in layers of $5 \mathrm{~mm}$ thickness, and it can remain exposed to occlusal forces.

The organic matrix of the Filtek Bulk Fill Posterior Restorative composite contains two new methacrylic monomers, which act synergistically to reduce the polymerization shrinkage. One of the monomers is a high molecular weight aromatic dimethacrylate (AUDM), which modulates the volumetric contraction. The second innovative monomer is actually a class of 
compounds called adhesion-fragmentation monomers (AFM) that contributes to the release of polymerization stress while maintaining the physical properties of the newly created polymer chains. The organic component also contains DDDMA (1,12-dodecanediol dimethacrylate) which provides low resin viscosity, decreasing exothermic reactions and polymerization shrinkage, and UDMA (urethane dimethacrylate), an increased molecular weight monomer, that reduces resin viscosity and polymerization shrinkage.

The inorganic component of Filtek Bulk Fill Posterior Restorative consists in a combination of nonagglomerated/non-aggregated silica particles of 20 nm, non-agglomerated/non-aggregated zirconia particles with sizes ranging from 4 to $11 \mathrm{~nm}$, respectively zirconia/silica clusters (containing $20 \mathrm{~nm}$ silica particles and 4 to $11 \mathrm{~nm}$ zirconia particles).

The inorganic component also includes ytterbium trifluoride aggregate particles of $100 \mathrm{~nm}$ (YbF3), which have the role of increasing radiopacity of the material. The total inorganic phase loading is about $76.5 \%$ (by weight), equivalent to $58.4 \%$ (by volume). Details about composite resins type, producer and chemical composition are presented in Table 1.

Twenty cylindrical samples $5 \mathrm{~mm}$ in diameter and $2 \mathrm{~mm}$ thick were made using plastic moulds The conformers were placed in tight contact with a celluloid matrix between two glass plates, in order to obtain a smooth, flat and a surface free of pores. The samples were lightcured for $40 \mathrm{~s}$ on both sides through glass plate to ensure complete polymerization of the material, using a light emitting diode light curing device (Optilight LD MAX -Gnatus) heaving a wavelength of $470 \mathrm{~nm}$ to 480 $\mathrm{nm}$, a maximum power of $600 \mathrm{~mW} / \mathrm{cm}^{2}$ and providing a polymerization depth of up to $3 \mathrm{~mm}$. After removing samples from moulds they were randomly divided into 4 groups. Samples from group 1 (control), were not finished or polished and the samples in groups 2-4, were finished and polished using three different systems.

In group 2, samples were firstly contoured and finished using tungsten carbide burs from Komet Dental/Gebr Brasseler $\mathrm{GmbH} \& \mathrm{Co}$. KG, Germany in the following order: for the coarse finishing step (cut-off) the H135Q bur, batch 906561 was used and for ultra-fine finishing (contouring) the H135UF bur, batch 903481 (ISO 500314166031014) was used. Each bur was used for 30 seconds, at 20,000 rpm and under continuous water cooling. Burs were driven in one direction, clockwise. Subsequent polishing was performed with a one-step polishing system Occlubrush (KerrHawe SA, Switzerland) made of polycarbonate fibers impregnated with silicon carbide particles. The small cup brushes were used at 5000 rpm, for 30 seconds and without polishing paste.

In group 3, samples were contoured and finished using the $\mathrm{H} 135 \mathrm{Q}$ and H135UF carbide burs (Komet Dental/Gebr Brasseler GmbH \& Co. KG, Germany). The polishing was done with a two-step polishing system Sof-Lex (3M ESPE). This system is made up of disposable spiral wheels for finishing (the beige one) and polishing (the white one). The lamellar discs are made of a thermoplastic elastomer impregnated with aluminium oxide particles. Each lamellar disk was used once for each sample, for 30 seconds, without paste or
I Table 1. Details about tested material

\begin{tabular}{|c|c|c|c|}
\hline \multirow{3}{*}{$\begin{array}{r}\text { Material/ } \\
\text { Manufacturer/ } \\
\text { Type/ } \\
\text { Batch No./ } \\
\text { Shade }\end{array}$} & \multirow{3}{*}{ Matrix } & \multicolumn{2}{|c|}{ Chemical composition } \\
\hline & & \multicolumn{2}{|c|}{ Filler Load: 76.5 wt\% / 58.4 vol\% } \\
\hline & & Type & Size \\
\hline $\begin{array}{r}\text { Filtek Bulk } \\
\text { Fill Universal } \\
\text { Restorative }\end{array}$ & $\begin{array}{r}\text { bis-GMA, } \\
\text { AUDM, }\end{array}$ & $\begin{array}{r}\text { Non-agglomerated/ } \\
\text { non-aggregated silica } \\
\text { particles }\end{array}$ & $\begin{array}{r}20 \\
\mathrm{~nm}\end{array}$ \\
\hline $\begin{array}{r}\text { 3MESPE, } \\
\text { St.Paul, MN, } \\
\text { USA }\end{array}$ & $\begin{array}{r}\text { AFM, } \\
\text { DDDMA } \\
\text { UDMA, }\end{array}$ & $\begin{array}{r}\text { Non-agglomerated/ } \\
\text { non-aggregated zirconia } \\
\text { particles }\end{array}$ & $\begin{array}{r}4-11 \\
\mathrm{~nm}\end{array}$ \\
\hline N720858/ A3 & $\begin{array}{r}\text { TEGDMA, } \\
\text { bis- } \\
\text { EMA(6) }\end{array}$ & $\begin{array}{r}\text { Clusters of aggregated } \\
\text { silica and zirconia particles } \\
\text { Ytterbium trifluoride } \\
\text { aggregate particles }\end{array}$ & $\begin{array}{l}100 \\
\mathrm{~nm}\end{array}$ \\
\hline
\end{tabular}

Bis-GMA: Bisphenol A diglycidyl ether dimethacrylate; AUDM: aromatic dimethacrylate; AFM: adhesion-fragmentation monomers; DDDMA: 1,12-dodecanediol dimethacrylate; UDMA: urethane dimethacrylate; TEGDMA: Triethyleneglycoldimethacrylate; bis EMA(6): ethoxylated bisphenol-A dimethacrylate.

water cooling, at speed of 20,000 r.p.m. according to the manufacturer's specifications.

In group 4, samples were contoured and finished using the H135Q and H135UF burs (Komet Dental/ Gebr Brasseler GmbH \& Co. KG, Germany). Subsequent polishing was performed with the multi-step Super Snap System (Shofu, Inc. Kyoto, Japan). This system consists of discs for contouring, finishing, polishing and superpolishing. The discs are manufactured without a metallic ring, do not expose the mandrel to the active surface, and they are impregnated with aluminium oxide powder of different grain size. For the present study, the purple finishing discs, the green polish and the pink ones for super-polish were used successively. Each abrasive disc was used once for each sample, without water spraying, without paste, for 30 seconds and the hand-piece was used at a speed of 10,000-20,000 rpm.

Finally, the samples were cleaned from the debris by washing with distilled water and dried with air. Subsequently, they were subjected to qualitative surface evaluation using the scanning electron microscope VEGA II LSH TESCAN (Czech Republic) and to quantitative profilometric analysis using a profilometer Taylor Hobson-Surtronic 25 (Ametek Inc, Berwyn, PA, USA). Ten traces were registered in different areas with a tip load of $0.75 \mathrm{mN}$, a tip diameter of $10 \mu \mathrm{m}$, a trace length of $0.25 \mathrm{~mm}$, a scanning speed of $0.5 \mathrm{~mm} / \mathrm{s}$ and a cut-off length of $0.8 \mu \mathrm{m}$.

The roughness parameters were calculated and the mean arithmetic deviation, $\mathrm{Ra}$, of the assessed profile was used. The Kolmogorov-Smirnov normality test was used to determine the distribution of data in groups. ANOVA and Tukey post hoc statistical tests were used to compare the results in groups.

\section{Results}

Some SEM surface images at different magnification with morphological aspects of Filtek Bulk Fill composite resin samples in groups 1-4 are presented in Fig. 1. In group 1 - Fig. 1a) (control samples), very rare micro-voids may be observed in small magnification $(500 \times)$, which can be inferred as arising from the sample preparation technique, 


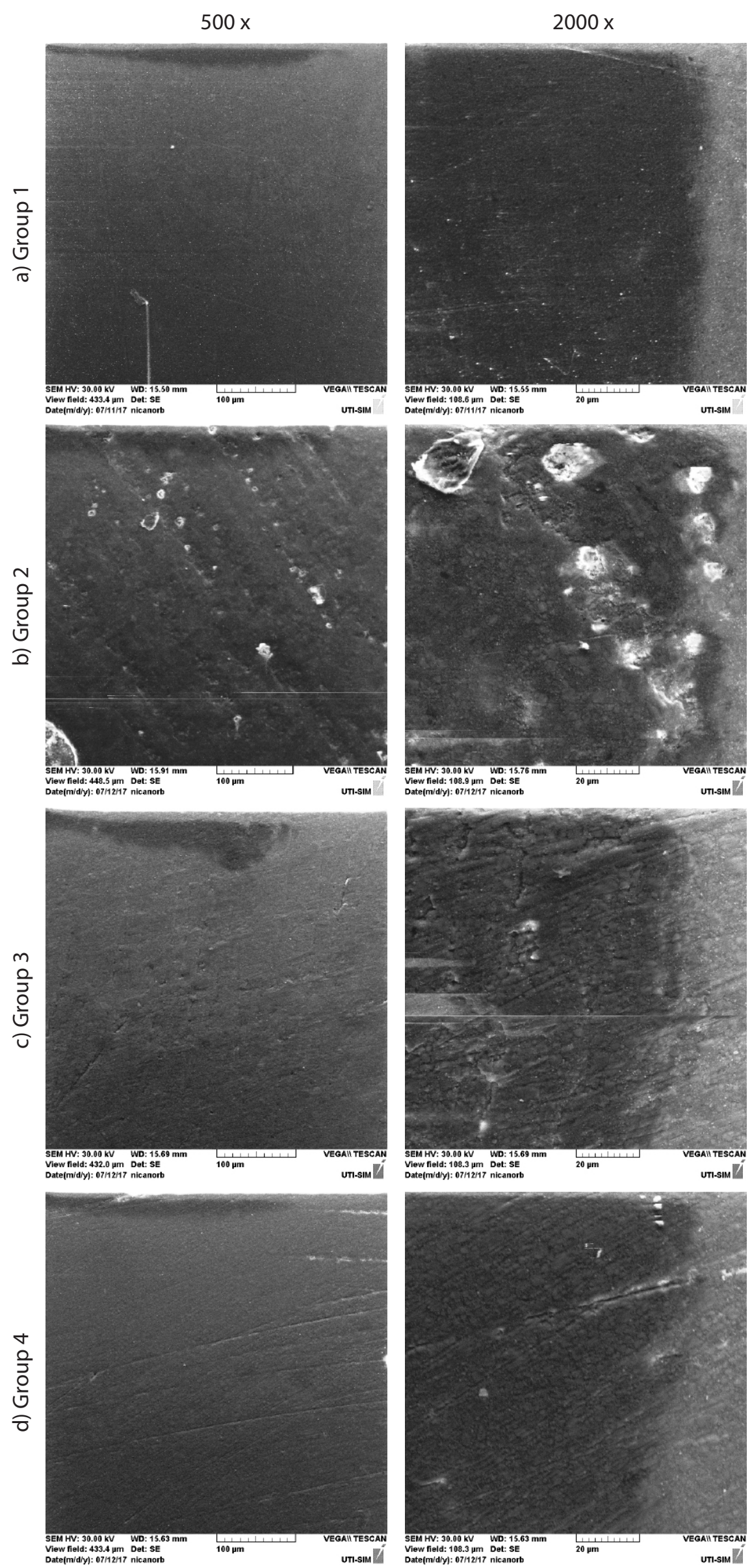

I Figure 1.SEM surface images of Filtek Bulk Fill composite resin at different magnification: a) control group, b-d) after finishing with the three finishing and polishing systems. 


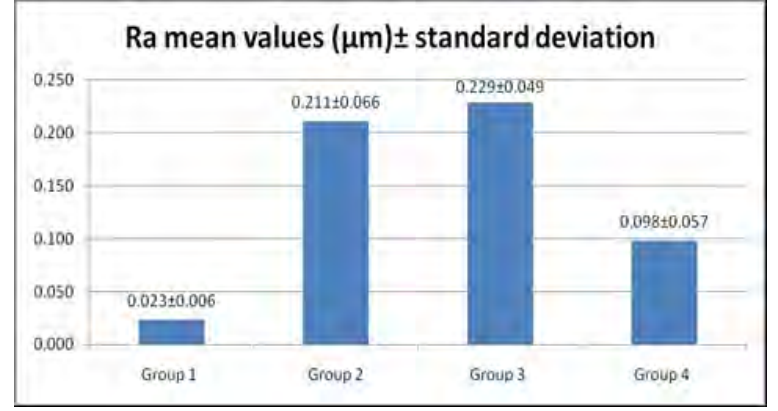

I Figure 2. Mean values of Ra parameter of Filtek Bulk Fill in control group and after finishing and polishing.

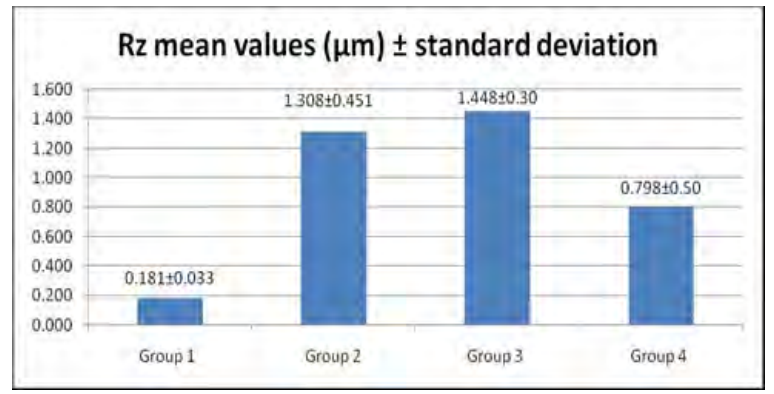

I Figure 3. Mean values of Rz parameter of Filtek Bulk Fill in control group and after finishing and polishing.

I Table 2. The Kolmogorov-Smirnov normality test result. One-Sample Kolmogorov-Smirnov Test

\begin{tabular}{|c|c|c|}
\hline & & method \\
\hline$N$ & & 41 \\
\hline \multirow[t]{2}{*}{ Normal Parameters ${ }^{a, b}$} & Mean & .14032 \\
\hline & Std. Deviation & .096316 \\
\hline \multirow[t]{3}{*}{ Most Extreme Differences } & Absolute & .159 \\
\hline & Positive & .159 \\
\hline & Negative & -.103 \\
\hline Kolmogorov-Smirnov Z & & 1.019 \\
\hline Asymp. Sig. (2-tailed) & & .250 \\
\hline
\end{tabular}

I Table 3. ANOVA statistical test result.

ANOVA

method
\begin{tabular}{|l|r|r|r|r|r|}
\hline & \multicolumn{1}{c|}{$\begin{array}{c}\text { Sum of } \\
\text { Squares }\end{array}$} & \multicolumn{1}{c|}{ df } & Mean Square & F & Sig. \\
\hline Between Groups & .276 & 3 & .092 & 35,949 & 000 \\
Within Groups & .095 & 37 & .003 & & \\
Total & .371 & 40 & & & \\
\hline
\end{tabular}

I Table 4. Tukey post hoc statistical test result. Post Hoc Tests

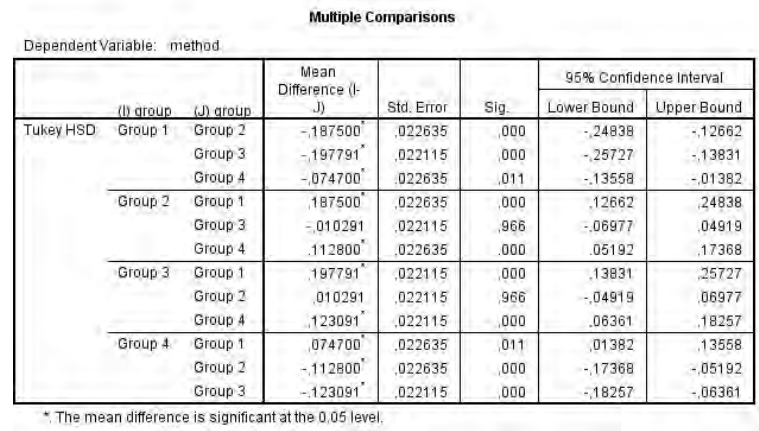

rather than from the polymerization shrinkage. At this magnification, the surface of control samples appears to be much smoother compared to the other samples. At larger magnifications $(2000 \times)$ very small particles can be identified, not aggregated, distributed among larger particles of silica and zirconia. The appearance of the surface seems compact, revealing a close adhesion between the organic matrix and the inorganic load.

For group 2 - Fig. 1b), the microstructure presents many parallel micro-channels 1 micrometer wide and a 10 micrometers mean distances between them. It is observed that the very fine particles on the surface and matrix elements were removed by abrasion, leaving large clusters with the diameter up to $5 \mu \mathrm{m}$ to be visible. Similar aspects are also observed in group 3 - Fig. 1c), but the micro-channels formed appear more accentuated and closer when compared to group 2. In group 4, the analyzed surface microstructure - Fig. 1d) indicates similar aspects, but the micro-channels are finer and rarer when compared to the samples from previous groups.

The mean $\mathrm{Ra}$ and $\mathrm{Rz}$ values obtained by quantitative assessment of samples surface using profilometry are represented in Fig. 2 and Fig. 3, respectively. The lowest $\mathrm{Ra}(0.023 \mu \mathrm{m})$ and $\mathrm{Rz}(0.181 \mu \mathrm{m})$ values were obtained in group 1. In group 2, increased $R a$ and $R z$ values were found (Ra mean value of $0.211 \mu \mathrm{m}$ and mean $\mathrm{Rz}$ value of $1.308 \mu \mathrm{m})$. In group 3 the same increase in the Ra and $R z$ mean values was observed ( $R a$ of $0.229 \mu \mathrm{m}$ and Rz of $1.448 \mu \mathrm{m})$. In group 4 the mean $\operatorname{Ra}(0.098 \mu \mathrm{m})$ and $\mathrm{Rz}(0.798 \mu \mathrm{m})$ values were much lower when compared to groups 2 and 3 , but higher than the control samples. The result of the Kolmogorov-Smirnov normality test showed that in all groups the data were normal distributed ( $p=0.250>0.05$ ) (Table 2). In order to compare the results in groups, ANOVA and Tukey post hoc statistical tests were used (Table 3 and 4, respectively).

Significant results were obtained when comparing $\mathrm{Ra}$ values in groups 2,3 , and 4 to group 1 ( $p<0.05$, Table 4). Also, statistically significant results were obtained when comparing the surface roughness in group 2 to group 4 and in group 3 to group 4. The results in group 2 were not statistically significant when compared to group 3 ( $p>0.05$, Table 4$)$.

\section{Discussion}

The type of inorganic filler of the material can influence the handling characteristic and the final surface aspect after finishing and polishing procedure. Some in vitro studies revealed that a number of other factors may influence the surface condition of the material, such as the type of finishing and polishing system: in one step or several steps $[9,10]$. It is a lack of consensual opinion in the literature regarding the effect of one step or multi-steps polishing system on composite resins surface roughness. It has been demonstrated that multi-step systems determined smoother surfaces than two-step systems or one-step systems [11]. On the other hand, some other studies showed that there are no significant differences between one-step and multi-step systems [12].

In the present study, the surface roughness of control samples was lower when compared to the results obtained for each of the three finishing and polishing systems used. These results are in agreement with a series of studies which have shown that the smoothest composite resin surface is obtained when the material is light-cured in tight contact with a celluloid matrix [1315]. The superficial layer, polymerized in contact with 
the celluloid matrix has a higher organic content than the underlying layer [16-18] and the removal of this layer by finishing and polishing procedure will increase the surface resistance of the material $[19,20]$. However, the anatomical contour of the restoration is rarely achieved only by the use of the celluloid matrix [21,22], so most of the time it is necessary to use the finishing and polishing instruments to remove the material in excess and to obtain the shape and the appearance of the restoration closer to the natural tooth.

In order to be effective, a finishing system has to contain abrasive particles with higher hardness than the inorganic filler particles of the composite. Otherwise, during the finishing and polishing steps, the resin-rich superficial layer (which has poor physical and mechanical properties) will be removed, and the filler particles will remain into bold relief on the surface layer [23,24]. Composites containing small filler particles will provide after finishing and polishing a smoother surface than the ones containing larger-sized filler particles $[25,26]$.

It was demonstrated that a composite surface roughness higher than $0.2 \mu \mathrm{m}$ will prone the composite surface to bacterial plaque retention, increased risk for secondary caries onset and for periodontal inflammation, and will affect the aesthetic aspect and the longevity of the restoration [27]. Some studies have shown that many of the finishing and polishing systems on the market lead to a smooth surface, with mean Ra values varying from $0.02 \mu \mathrm{m}$ to $0.56 \mu \mathrm{m}$ [28, 29]. In our study using tungsten carbide burs with the one-step polishing system Occlubrush and tungsten carbide burs with the two-step Sof-Lex finishing system determined the Ra mean value to slightly increase over $0.2 \mu \mathrm{m}$. When using tungsten carbide burs and the multi-step Super Snap system, the mean Ra value was lower than $0.2 \mu \mathrm{m}$. We can assume that the effect of the finishing and polishing protocol used in this study had a notable clinical significance.

The complex surface structure of a composite resin cannot be fully characterized only by using profilometry. A clear prediction of clinical performance of a restorative material can be made by correlating the roughness parameters calculated by the profile geometry with the morphological surface analysis by scanning electron microscopy, which allows assessing the destructive potential of different finishing and polishing systems $[30,31]$. Since the quality of the final restoration surface is influenced by the type of the instrument used for finishing and polishing and also by the material structure, choosing the most suitable instrument for a specific material seems to become of great clinical importance.

\section{Conclusion}

1. For Filtek Bulk Fill Posterior (3M ESPE), the smoothest surface was obtained when the material was placed in direct contact with the celluloid matrix.

2. The use of tungsten carbide burs followed by multistep Super Snap finishing system determined a lower surface roughness than with the other polishing systems. 3. Finishing with tungsten carbide burs and two-steps Sof-Lex polishing system and one-step polishing system Occlubrush determined, significantly higher surface roughness than t multi-step Super Snap system.

4. The surface characteristics of the studied composite resin were influenced by the type of finishing and polishing system used.

\section{Author contributions}

Equal contribution to the paper.

\section{Acknowledgement}

Not applicable. The study was self-funded.

\section{References}

1. Raj R, Gupta R. In vitro evaluation of the effect of two finishing and polishing systems on four esthetic restorative materials. J Conserv Dent. 2013;16(6):564-567. doi: 10.4103/0972-0707.120946. [Full text links] [Free PMC Article] [PubMed] Google Scholar(20) Scopus(10)

2. Yap AU, Yap SH, Teo CK, Ng J. Comparison of surface finish of new aesthetic restorative materials. Oper Dent. 2004;29(1):100-104. [PubMed] Google Scholar(110) Scopus(47)

3. Stoleriu S, lovan G, Pancu G, Nica I, Andrian S. Study concerning the influence of the finishing and polishing systems on the surface state of various types of composite resins. Rom J Oral Rehab. 2013;5(3):78-83 Google Scholar(2)

4. Erdemir U, Sancakli HS, Yildiz E. The effect of one-step and multi-step polishing systems on the surface roughness and microhardness of novel resin composites. Eur J Dent. 2012;6(2):198-205.

[Free PMC Article] [PubMed] Google Scholar(41) Scopus(17)

5. Nica I, Stoleriu S, lovan G, Pancu G, Andrian S. Fractal analysis of some restorative Nano-filled composite materials microstructure. Stoma Edu J. 2015;2(1):36-43. Google Scholar(2)

6. Takanashi E, Kishikawa R, Ikeda M, et al. Influence of abrasive particle size on surface properties of flowable composites. Dent Mater J. 2008;27(6):780-786.

[Full text links] [PubMed] Google Scholar(24) Scopus(16)

7. Yazici AR, Muftu A. Three dimensional surface profile analysis of different types of flowable restorative resins following different finishing protocols. J Contemp Dent Pract. 2007;8(5):1-11. [PubMed] Google Scholar(20) Scopus(9)

8. Attar N. The effect of finishing and polishing procedures on the surface roughness of composite resin materials. J Contemp Dent Pract. 2007:8(1):27-35.

[PubMed] Google Scholar(119) Scopus(51)

9. Jefferies SR. Abrasive finishing and polishing in restorative dentistry: a state of art review. Dent Clin North Am. 2007;51(2):379-397, ix. doi: 10.1016/j.cden.2006.12.002 [Full text links] [PubMed] Google Scholar(135) Scopus(51)

10. Efreifej NS, Oweis YG, Eliades G. The effect of polishing technique on 3-D surface roughness and gloss of dental restorative resin composites. Oper Dent. 2013;38(1):9-20.

[Full text links] [PubMed] Google Scholar(26) Scopus(15)

11. Jung M, Sehr K, Klimek J. Surface texture of four nanofilled and one hybrid composite after finishing. Oper Dent. 2007;32(1):4552. doi: 10.2341/06-9.

[Full text links] [PubMed] Google Scholar(107) Scopus(48)

12. Yap AU, Mok BY. Surface finish of a new hybrid aesthetic restorative material. Oper Dent. 2002;27(2):161-166. [PubMed] Google Scholar(75) Scopus(45)

13. Sarac D, Sarac YS, Kulunk S, Ural C, KulunkT. The effect of polishing techniques on the surface roughness and color change of composite resins. J Prosthet Dent. 2006;96(1):33-40. doi: 10.1016/j. prosdent.2006.04.012

[Full text links] [PubMed] Google Scholar(173) Scopus(67)

14. Uctasli MB, Bala O, Gull A. Surface roughness of flowable and packable composite resin materials after finishing with abrasive disc. J Oral Rehabil. 2004;31(12):1197-2002. doi:10.1111/j.13652842.2004.01341.x

[Full text links] [PubMed] Google Scholar(54) Scopus(24)

15. EndoT, Finger WJ, Kanehira M, Utterodt A, Komatsu M. Surface texture and roughness of polished nanofill and nanohybrid resin composites. Dent Mater J. 2010;29(2):213-223. [Full text links] [PubMed] Google Scholar(82) Scopus(34)

16. Grădinaru I, Ignat L, Dascălu CG, Soroaga LV, Antohe ME. Studies regarding the architectural design of various composites and nanofibres used in dental medicine. Rev Chim.(Bucharest). 2018;69(2):328-331. Google Scholar(0) Scopus(0) 
17. Joniot SB, Gregoire GL, Auther AM, Roques YM. Threedimensional optical perfilometry analysis of surface states obtained after finishing sequences for three composite resins. Oper Dent. 2000;25(4):311-315.

[PubMed] Google Scholar(87)

18. Pettini F, Corsalini M, Savino MG, et al. Roughness analysis on composite materials (Microfilled, Nanofilled and Silorane) after different finishing and polishing procedures. Open Dent J. 2015;9:357-367. doi: 10.2174/1874210601509010357. eCollection 2015.

[Free PMC Article] [PubMed] Google Scholar(7) Scopus(3)

19. Chinelatti MA, Thomazatti Chimello D, Pereira Ramos R, PalmaDibb RG. Evaluation of the surface hardness of composite resins before and after polishing at different times. J Appl Oral Sci. 2006;14(3):188-192.

[Full text links] [Free PMC Article] [PubMed] Google Scholar(25) Scopus(11)

20. Kumari CM, Bhat KM, Bansal R. Evaluation of surface roughness of different restorative composites after polishing using atomic force microscopy.J Conserv Dent. 2016;19(1):56-62.

[Full text links] [PubMed] Google Scholar(7) Scopus(7)

21. Venturini D, Cenci MS, Demarco FF, Camacho GB, Powers JM. Effect of polishing techniques and time on surface roughness, hardness and microleakage of resin composite restorations. Ope Dent 2006:31(1):11-17. doi: 10.2341/04-155

[Full text links] [PubMed] Google Scholar(116) Scopus(51)

22. Bittencourt Berger S, Muniz Palialol AR, Cavalli V, Giannini M. Surface roughness and staining susceptibility of composite resins after finishing and polishing. J Esthet Restor Dent. 2011;23(1):34-

43. doi: 10.1111/j.1708-8240.2010.00376.x.

[Full text links] [PubMed] Google Scholar(57)

23. Balan A, Sandu AV, Stoleriu S, Pintiliciuc VS, Toma V. Effect of different finishing and polishing systems on the surface roughness of composite resins. Rev Mat Plast. 2015;52(1):55-57. Google Scholar(4) Scopus(10)
24. Schmidlin PR, Göhring TN. Finishing tooth-colored restorations in vitro: an index of surface alteration and finish-line destruction. Oper Dent. 2004;29(1):80-86.

[PubMed] Google Scholar(30) Scopus(15)

25. Baciu ER, Ben Amor H, Calamaz D, Baciu M, Grădinaru I. Study regarding the profile of finished surfaces of some direct composite resins. Rom J Oral Rehab. 2016;8(3):19-25. Google Scholar(0)

26. Patel B, Chhabra N, Jain D. Effect of different polishing systems on the surface roughness of nano-hybrid composites. J Conserv Dent. 2016;19(1):37-40. doi: 10.4103/0972-0707.173192. [Full text links] [Free PMC Article] [PubMed] Google Scholar(4) Scopus(3)

27. Kakaboura A, Fragouli M, Rahiotis C, Silikas N.Evaluation of surface characteristics of dental composites using profilometry, scanning electron, atomic force microscopy and gloss-meter. J Mater Sci Mater Med. 2007;18(1):155-163. doi: 10.1007/s10856-006-0675-8 [Full text links] [PubMed] Google Scholar(162) Scopus(86)

28. Baroudi K, Rodrigues JC. Flowable resin composites: a systematic review and clinical considerations. J Clin Diagn Res. 2015;9(6):ZE18-24. doi: 10.7860/JCDR/2015/12294.6129. [Free PMC Article] [PubMed] Google Scholar(28) Scopus(6)

29. Baseren M. Surface roughness of nanofill and nanohybrid composite resin and ormocer-based tooth-colored restorative materials after several finishing and polishing procedures. J Biomater Appl. 2004;19(2):121-134. doi: 10.1177/0885328204044011

[Full text links] [PubMed] Google Scholar(144) Scopus(69)

30. Ergücü Z, Türkün LS. Surface roughness of novel resin composites polished with one-step systems. Oper Dent. 2007:32(2):185-192 doi: 10.2341/06-56

[Full text links] [PubMed] Google Scholar(107) Scopus(51)

31. Uctasli MB, Arisu HD, Omürlü $\mathrm{H}$, et al. The effect of different finishing and polishing systems on the surface roughness of different composite restorative materials. J Contemp Dent Pract. 2007;8(2):89-96.

[PubMed] Google Scholar(57) Scopus(18)

\section{Irina NICA}

DMD, MSc, PhD, Assistant Professor

Department of Odontology - Periodontology and Fixed Prosthodontics Faculty of Dental Medicine, "Grigore T. Popa" University of Medicine and Pharmacy

Jassy, Romania

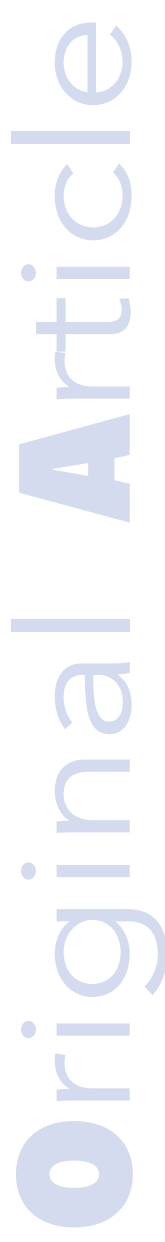

Doctor Irina Nica is Assistant Professor of Cariology and Operative Dentistry at the Faculty of Dental Medicine, "Gr. T. Popa" University of Medicine and Pharmacy Jassy, Romania. She graduated from the Faculty of Stomatology of the "Gr. T. Popa" University of Medicine and Pharmacy, Jassy (2001). She is a Board Certified Physician in the specialty "General Stomatology" (2005). In 2012 she obtained her PhD title in medical sciences with a thesis entitled"Theoretical and experimental contributions to nanomaterials usage in dental medicine". Her main research field is Restorative Dentistry.

\section{A smooth surface of the composite restoration is very important for:}

$\square$ a. Preventing biofilm accumulation;

b. Maintaining oral health;

bc. Preventing external staining;

d. All the previous answers are correct.

\section{The two steps polishing system used in the present study was:}

口a. Tungsten Carbide Burs H135Q and H135UF (Komet Dental/Gebr Brasseler GmbH \& Co. KG, Germany); b. Occlubrush system (KerrHawe SA, Switzerland);

口c. Sof-Lex system (3M ESPE);

d. Super Snap system (Shofu, Inc. Kyoto, Japan).

\section{The action of the instrument used for finishing and polishing determines different values of roughness parameters by:}

a. The hardness of the abrasive powder;

b. The diameter of the particles from which it is made;

c. The flexibility of the substrate on which the abrasive powder is impregnated;

$\square$ d. All the previous answers are correct.

\section{The surface microstructure of Filtek Bulk Fill composite was evaluated:}

a. Qualitatively by AFM (Atomic Force Microscopy);

b. Quantitatively by Profilometry;

口c. Qualitatively by MO (Optical Microscopy);

ad. Quantitatively by SEM (Scanning Electron Microscopy). 